\title{
Una respuesta basada en la armonización ética al problema de la reconciliación
}

Recibido: 18/01/2021 | Revisado: 19/03/2021 | Aceptado: 26/03/2021

DOI: 10.17230/co-herencia.18.34.4

\section{Oswaldo Juan Plata-Pineda* \\ ojplata@elpoli.edu.co}

Resumen La reconciliación suele ser definida como el proceso de restablecimiento de las relaciones que un conflicto ha perturbado. Esta perturbación ha sido asociada por la convención académica a la guerra o a la dictadura y analizada en la perspectiva de generar las condiciones para construir sostenidamente la paz. En el presente estudio ofrezco una respuesta al problema de reconciliación que, con fundamento en la noción de armonización ética, aporta una solución plausible a los conflictos que tienen lugar en contextos de transición institucional (en el marco de un proceso de construcción de paz) y en contextos interpersonales. Así, la respuesta basada en la armonización ética sostiene que es posible restablecer las relaciones después de un conflicto si los conjuntos de creencias enfrentados son armonizados por medio de un juicio en situación (sabiduría práctica) orientado a la materialización del objetivo ético -con y para otroen instituciones justas.

\section{Palabras clave:}

Reconciliación, armonización, ética, tensión, sabiduría práctica.

\section{A Response Based on Ethical Harmonization to the Problem of Reconciliation}

\footnotetext{
Abstract Reconciliation is defined as a process of reestablishing relationships that a conflict has disrupted. This disruption has been associated with academic conventions with regard to war or dictatorship and analyzed from the perspective of generating the conditions to sustainably build peace. In this stu$\mathrm{dy}$, I offer a response to the problem of reconciliation that provides a plausible solution to conflicts that take place in contexts of institutional transition (within the framework of a peace-building process) and in interpersonal contexts based on the notion of ethical harmonization. This response based on ethical harmonization posits that it is possible to reestablish relationships after conflict if conflicting sets of beliefs are harmonized by means of a
}

* Doctor en Filosofía Candidato a doctor en Humanidades.

Profesor del

Politécnico

Colombiano Jaime Isaza Cadavid. Medellín-Colombia. ORCID: 0000-0002. 1249-383X. 
judgment in the circumstances (practical wisdom) aimed at reali-

zing ethical objectives with and for another in just institutions.

\section{Keywords:}

Reconciliation, harmonization, ethics, tension, practical wisdom.

La reconciliación ha sido entendida recientemente como un criterio que mide el éxito de la transición de la guerra a la paz y el avance de la consolidación social e institucional de esta (Hazan, 2009). Los procesos de transición que tuvieron lugar en Sudáfrica, en Timor Leste, en los países del Cono Sur (Argentina, Chile y Uruguay) y en la antigua Yugoslavia son tomados con frecuencia como casos paradigmáticos de análisis para poner de manifiesto la íntima relación entre la construcción de paz y la reconciliación, así como para plantear la necesidad de arrojar luz sobre las formas específicas de la reconciliación en orden a evitar una recaída en el conflicto bélico (Little \& Maddison, 2017). La importancia de la reconciliación en procesos de construcción de paz es sustentada por la evidencia empírica en que no basta con la firma de un acuerdo de paz entre antiguos adversarios para que una transición institucional sea exitosa, ni suficiente para que se restablezcan las relaciones entre los miembros del cuerpo social (Soares de Oliveira, 2011). Así, contra la expectativa de documentos oficiales como la Agenda for Peace (Ghali, 1992), la experiencia ha demostrado que la construcción de paz constituye un proceso social y político que, más allá de un tratado de paz, enfrenta enormes dificultades relacionadas con las secuelas dejadas por el conflicto bélico (Ugarriza \& Nussio, 2017). Dichas secuelas impactan las dinámicas de los procesos de transición, provocan rupturas de relaciones en el cuerpo social y amenazan con forzar una recaída en el conflicto bélico (Paris, 2005). Por lo tanto, es plausible sostener que el éxito de la construcción de paz depende en buena medida de que las relaciones rotas por el conflicto se restablezcan (Auerbach, 2004; Bhargava, 2001; Brounéus, 2008).

El objetivo del presente estudio es aportar una respuesta a la pregunta por la reconciliación basada en la armonización ética y que es aplicable a conflictos que tienen lugar tanto en contextos de 
transición institucional (en el marco de un proceso de construcción de paz) como en contextos interpersonales. ${ }^{1}$ La respuesta basada en la armonización ética parte de la consideración de que la esencia de todo tipo de conflicto es la tensión entre la perspectiva de la primera persona y la perspectiva de la segunda persona. Por tensión entiendo la ausencia de armonía entre los conjuntos de creencias sostenidos por un agente A y un agente B. Así, la respuesta basada en la armonización ética plantea que es posible restablecer las relaciones humanas después de un conflicto si los conjuntos de creencias enfrentados son armonizados por medio de un juicio en situación (sabiduría práctica) orientado a la materialización del objetivo ético "con y para otro en instituciones justas" (Ricœur, 2013, p. 258).

Mi exposición se encuentra dividida en cinco apartados. En el primero afirmo que las acciones que un agente está dispuesto a hacer se siguen de un conjunto de creencias, no necesariamente coherente, y explico cómo el ejercicio de la agencia puede derivar en tensión cuando el conjunto de creencias profesado por un agente no logra ser armonizado con el profesado por otro agente. Llamo a esto tensión entre la perspectiva de la primera persona y la perspectiva de la segunda persona, y señalo que esta tensión es una característica esencial de todo conflicto. En el segundo apartado refiero una recurrente solución a la tensión entre la perspectiva de la primera persona y la perspectiva de la segunda persona consistente en la introducción de la perspectiva de la tercera persona. Sostengo allí que una solución efectiva a la tensión entre la perspectiva de

1 La pregunta por la reconciliación ha sido analizada a partir de nociones como (1) el perdón, (2) el respeto mutuo, (3) la justicia restaurativa o (4) la agencia recíproca. Estos análisis se centran en el contexto de transición institucional (esto es, de la guerra a la paz o de la dictadura a la democracia) y sostienen que el restablecimiento de las relaciones humanas es posible (1) si un agente (víctima) supera las emociones reactivas que le suscita una acción realizada por otro agente (victimario) (Schreiter, 2005); (2) si los agentes enfrentados en el pasado se reconocen recíprocamente como seres morales y dignos, y si las identidades construidas en el contexto del conflicto bélico se modifican de modo que no continúen siendo el soporte del relacionamiento entre agentes (Verdeja, 2009); (3) si se supera la injusticia política que, en el contexto de un conflicto bélico, socava la dignidad humana y destruye el correcto relacionamiento entre agentes (Philpott, 2012), o (4) si, a partir del esclarecimiento de las causas y condiciones históricas del conflicto, se restaura el estado de derecho, se garantizan las expectativas relacionales de confianza entre agentes/ciudadanos y se aseguran las oportunidades materiales y formales para los agentes ciudadanos (Murphy, 2010). 
la primera persona y la perspectiva de la segunda persona debería considerar, entre otras cosas, los aspectos permanentes y cambiantes de la identidad.

En el tercer apartado describo la teoría ricœuriana de la identidad personal que la asume cambiante, variable, y que otorga un lugar preponderante al otro. Esta teoría se apoya en la narrativa y establece la disociación de la identidad entre lo que permanece (ídem o mismidad) y lo que se transforma narrativamente en el tiempo (ipse o ipseidad). Afirmo que, al hacer de la teoría narrativa "el eje de la teoría de la acción y de la teoría moral" (Ricœur, 2013, p. 124), Ricœur conecta la capacidad de actuar en el mundo (agencia) con la capacidad de narrar ese mundo y la propia vida (agencia narrativa) y con la capacidad de realizar juicios sobre lo bueno y lo malo (agencia moral). En el cuarto apartado describo el significado que Ricœur le atribuye a la ética, y explico en qué consiste la primacía de ella sobre la moral. Muestro allí cómo los planteamientos éticos sustentados en la búsqueda de la vida buena (Aristóteles) y en la obligación de la norma moral (Kant) son armonizados por Ricœur a partir de la noción aristotélica de sabiduría práctica, la cual permite el recurso al objetivo ético cuando la norma conduce a aprietos prácticos. En el quinto apartado, con base en la hermenéutica de sí propuesta por Ricœur, detallo la manera como la respuesta basada en la armonización ética da cuenta de la pregunta por la reconciliación mediante un juicio en situación que dirime la contraposición entre principios o mandatos de acción de equivalente estatuto epistémico y normativo.

1. La agencia es la capacidad humana de actuar en el mundo. Dictar una conferencia, correr una maratón, asistir a una reunión o comprar un electrodoméstico son expresiones concretas de esta agencia. En cuanto capacidad, la agencia puede ser ejercida o no. Por tanto, ni su existencia ni su posibilidad de despliegue son puestas en cuestión por su no ejercicio.

La vida humana es llevada a cabo por medio de acciones derivadas del ejercicio de la agencia. No todas las veces este ejercicio es consciente y deliberado. Aun así, se puede identificar y valorar a un agente a partir de las acciones que él lleva a cabo. Salvo en casos excepcionales, las acciones que desarrolla un agente se siguen de sus 
creencias. No se trata necesariamente de creencias organizadas en un conjunto único y coherente (Peirce, 1988).

El conjunto de creencias de un agente está conformado por creencias de todo tipo. Es así como un agente puede creer que la tierra es plana, que Jackson Pollock es un pintor sobreestimado o que América de Cali es un buen equipo de fútbol. Es posible que muchos agentes profesen conjuntos de creencias internamente incoherentes o que no se hallen sustentados en argumentos racionales o en evidencia empírica. Un conjunto de creencias debe cumplir ante todo la función de dar soporte y orientación a cada acción adelantada, tornando expedito el tránsito del agente en el mundo. Desde luego, es dable que las creencias no se encuentren estructuradas de un modo coherente. De hecho, es posible que un agente considere que su conjunto de creencias, además de ser funcional al tránsito eficiente en el mundo, se encuentra soportado en razones sólidas.

Para evidenciar la manera en que funciona en la cotidianidad una creencia, considérese el siguiente caso. Un agente cree que el girasol es la flor más bonita del mundo. Esta es una creencia de naturaleza estética y su alcance es individual. Nadie considerará ese juicio aberrante o amenazador. Es una creencia que simple y llanamente motiva la emisión del juicio "el girasol es la flor más bonita del mundo" y que promueve la acción de comprar girasoles para adornar la casa. Este tipo de creencias no aspira a una verdad objetiva.

Sin embargo, un agente puede profesar creencias de mayor calado: creer, por ejemplo, en la omnipotencia de Dios, en la conveniencia de un modelo específico de organización social y económica, o en la transmigración de las almas en el tiempo. Estas creencias se articulan al propósito superior de alcanzar la realización plena del ser. En la consecución de dicho propósito, las creencias cumplen la función de soportar y orientar el tránsito del agente hacia la realización plena de su ser. Que un agente profese un conjunto de creencias no significa en todo caso que su tránsito en el mundo sea exitoso de antemano. Exitoso es un tránsito que es compatible con las expectativas derivadas de un elenco de creencias específicas. El profesar un conjunto de creencias, organizado o no, solo garantiza una orientación, un camino, un telos. 
Factores internos y externos influyen en el éxito de un curso de acción desprendido del conjunto de creencias de un agente. Los factores internos guardan relación con la escogencia de los medios, con la pertinencia temporal de las decisiones y las acciones, con las definiciones de las metas o con la persistencia de los cursos de acción establecidos. Todos estos factores conciernen al agente. Los factores externos refieren, por su parte, la acción que otro agente desarrolla, deliberadamente o no, en contra del ejercicio de la agencia del yo. Se trata en este caso de acciones realizadas por otro que obstaculizan las acciones del yo. Llamo a esto tensión entre la perspectiva de la primera persona y la perspectiva de la segunda persona. La perspectiva de la primera persona constituye el conjunto de creencias que disponen al yo a actuar y que son expresadas en oraciones como "Yo creo que la libertad es la máxima virtud de la sociedad”. A su vez, la perspectiva de la segunda persona refiere el conjunto de creencias que disponen al otro a actuar y que son expresadas en oraciones como "Tú crees que la igualdad es la máxima virtud de la sociedad". Se sigue de esto que lo que llamo tensión (1) es producto del ejercicio no armónico de las agencias del yo (perspectiva de la primera persona) y del otro (perspectiva de la segunda persona) y (2) constituye la característica esencial de todo conflicto. Amén de su índole y su contenido, todo conflicto humano es manifestación de la tensión entre la perspectiva de la primera y la perspectiva de la segunda persona.

Ilustremos lo anterior mediante el caso de dos vecinos de un edificio, uno católico y el otro protestante. A lo largo del tiempo, su convivencia ha sido cordial y armónica. No son amigos, pero tampoco enemigos. Sin embargo, ambos creen que la interpretación de la doctrina cristiana de su vecino es equivocada. Las diferencias conciernen a asuntos doctrinarios y eclesiológicos. Movidos por sus respectivas creencias, que animan a compartir la Buena Nueva con el prójimo, los dos agentes harán todo cuanto esté a su alcance para persuadir a su vecino acerca de la validez de su propia interpretación de la Palabra de Dios. El espectro de este proceso de persuasión irá desde la predicación cordial de pasajes bíblicos específicos hasta el rechazo enérgico a la exégesis de su vecino, y el resultado del proceso dependerá de la manera como sus respectivas acciones y sus 
conjuntos de creencias se armonicen. De este modo, si no existe un debido tratamiento de estas diferencias, de esta tensión, es posible que se desate una confrontación que dé al traste con la armonía entre los vecinos.

A partir de lo anterior, parece razonable suponer que la tensión tendrá lugar en un contexto que involucre ya no a dos agentes-vecinos (a saber, la perspectiva de la primera persona y la perspectiva de la segunda persona), sino a grupos de agentes que profesan conjuntos antagónicos de creencias. En tal contexto, sin un debido tratamiento de las diferencias, la armonía entre agentesconciudadanos se tornará también imposible y se iniciará una escalada de conflictividad bélica (Brounéus, 2008). En el próximo apartado, ahondaré justamente en los efectos colectivos de la tensión y en cómo tales efectos han sido enfrentados.

2. En el anterior apartado expuse que la capacidad de un agente de actuar en el mundo (agencia) se fundamenta en un conjunto de creencias, y mencioné que el ejercicio que hace el yo de esta agencia no siempre armoniza con el ejercicio que de esta agencia hace otro agente. A esta desarmonía entre agencias (y, más aún, entre conjuntos de creencias) la denominé tensión entre la perspectiva de la primera persona y la perspectiva de la segunda persona, y afirmé que esta tensión constituye la característica esencial de todo conflicto. En el presente apartado presento una solución recurrente a la tensión producida entre la perspectiva de la primera persona y la perspectiva de la segunda persona que consiste en la introducción de la perspectiva de la tercera persona y que se funda en una concepción estática de la identidad. Mi objetivo en este apartado es doble: primero, demostrar que la tensión entre la perspectiva de la primera persona y la perspectiva de la segunda persona, característica esencial de todo conflicto, provoca cambios significativos en las identidades de los agentes; y, segundo, anticipar la tesis de que una teoría de la reconciliación que pretenda responder a la pregunta de cómo es posible el restablecimiento de las relaciones humanas debe por necesidad dar cuenta del efecto que la tensión provoca en las identidades de los agentes involucrados en el conflicto.

En el siglo XVII, Thomas Hobbes descartó que la armonía social 
entre agentes fuera posible, incluso en condiciones de simetría. Describiendo lo que denominó la condición natural de la humanidad, Hobbes planteó que, sin poder común, todas las relaciones entre agentes derivan en una "situación de guerra de todos contra todos" (1994, p. 116) en la que la vida se convierte en "solitaria, pobre, desagradable, brutal y corta" (p. 115). Con base en esto, Hobbes justificó la creación de un estado político (gobernado por ese Dios mortal que es el Leviatán) que asegurara la convivencia armónica entre un agente y otros agentes.

En el siglo XVIII, Immanuel Kant abordó este mismo problema, aunque ofreciendo una salida política diferente a la de Hobbes. A pesar de haber identificado la insociable insociabilidad como un rasgo constitutivo de la relación entre agentes, Kant creyó que la tensión entre agentes -que la Naturaleza ha concebido- podía superarse si se adoptaba el punto de vista de la razón. Así, Kant argumentó a favor del poder determinador de la razón sobre la voluntad humana y sostuvo que la ley moral permitiría el "enlace sistémico de distintos seres racionales por leyes comunes" (1996, pp. Ak, Iv, 433) y allanaría la creación de "una constitución civil perfectamente justa" (Kant, 1985, p. 49).

En los inicios de la Era Común, Pablo de Tarso ofreció una solución a este problema de la tensa relación entre agentes. A diferencia de Hobbes y de Kant, Pablo de Tarso partió de un vínculo indisoluble entre los hombres que deviene inmediato de su condición de hijos de Dios. Así, la separación entre ellos no es sino aparente, toda vez que el "espíritu de Dios" los une y los hace sus hijos (Romanos 8: 12-25). Aun cuando está establecido que se debe "estar en paz con todos los hombres" (Romanos 12: 18), ello no obsta para que surjan desvíos en el cumplimiento de la Ley ("por cuanto todos pecaron, y están destituidos de la gloria de Dios"; Romanos 3: 23-24) y que las relaciones se tornen tensas y se produzcan ofensas. La solución paulina consistió en la superación de la letra de la Ley y en la recuperación de su espíritu. Es mediante esto que el hombre puede servir "bajo el régimen nuevo del Espíritu y no bajo el régimen viejo de la letra" (Romanos 7: 6), convivir horizontalmente con los otros hombres ("Así que, si tu enemigo tuviere hambre, dale de comer"; 
Romanos 12: 20) y dirigir sus acciones a "alcanzar [la] salvación por medio de nuestro Señor Jesucristo" (1 Tesalonicenses 5: 9).

Hobbes, Kant y Pablo de Tarso plantearon perspicuas soluciones al problema de la tensión entre la perspectiva de la primera persona y la perspectiva de la segunda persona. La de Hobbes es una salida institucional-instrumental que deriva en un estado político de querencia autoritaria. La de Kant es una salida institucional-moral que, al paso de la introyección de la ley moral, conforma una identidad colectiva de orden supramoral. Finalmente, la solución de Pablo de Tarso es institucional-religiosa y plantea un nuevo Ahora que actualiza la hermandad entre los hombres y que dirige las acciones humanas hacia la salvación (Dussel, 2012).

Así, en cada caso, la tensión entre la perspectiva de la primera persona y la perspectiva de la segunda persona es superada por medio de la introducción de la perspectiva de la tercera persona, esto es, de una entidad mediadora de la divergencia humana que garantiza la convivencia armónica: el Leviatán en Hobbes, la Ley moral en Kant y el espíritu de la Ley en Pablo de Tarso. La perspectiva de la tercera persona refiere una instancia que, desde afuera, juzga las acciones del agente con independencia de las formas de experiencia práctica. En los tres casos, es similar el esquema de planteamiento y de solución al problema de la tensión entre la perspectiva de la primera persona y la perspectiva de la segunda persona. También es similar la identidad del yo implícita a cada una de estas soluciones. Veamos.

Hobbes define al hombre como un ser disociado de los otros hombres, dotado de razón, "que no es otra cosa que un calcular" (Hobbes, 1994, p. 46), y abocado a asegurar su autoconservación. Nada cuanto acontece después de la situación de guerra de todos contra todos afecta o modifica esa identidad. Así, Hobbes plantea la constitución de un poder común garante de la vida dejando la identidad del hombre aséptica de alteridad.

Por su parte, Kant plantea una concepción racional del hombre que es susceptible del influjo de las inclinaciones sobre la voluntad. La identidad del hombre deviene del vínculo racional que el imperativo categórico aspira a recuperar, desactivando el influjo de esas inclinaciones y configurando el reino de los fines. 
Todo cuanto acontece después de la introyección de la ley moral potencia la identidad del hombre y lo convierte en una conciencia moral (blindada ante el influjo de las inclinaciones) en la que él, el otro y los otros se encuentran contenidos. Así, Kant plantea una solución que potencia la identidad de todos los seres racionales en una supraidentidad moral y racional.

Finalmente, Pablo de Tarso insiste en una identidad del hombre subsidiaria de Dios: "Pero tenemos este tesoro en vasos de barro, para que la excelencia del poder sea de Dios, y no de nosotros" (2 Corintios 4: 7). El hombre, el otro y los otros están contenidos en la Divinidad y sus identidades devienen de ella. Nada cuanto acontece en el mundo material modifica el ser hijo de Dios y ser hermano de los otros hombres. Así, las tensiones y las ofensas podrán tener un efecto sobre los destinos finales de cada hombre, pero no menoscabar la identidad de espíritu con Dios y con los otros hombres. Porque "si siendo enemigos, fuimos reconciliados con Dios por la muerte de su Hijo, mucho más, estando reconciliados, seremos salvos por su vida" (Romanos 5: 10-11).

Llama la atención que las tres soluciones mencionadas asuman que la tensión entre la perspectiva de la primera persona y la perspectiva de la segunda persona, así como la introducción de la perspectiva de la tercera persona para resolver tal tensión, no traiga consigo una modificación ostensible en la identidad del hombre. Esta no afectación es evidente en Hobbes, pues la transición del estado de naturaleza al estado político no provoca transformaciones en la voluntad del hombre, ni la privación de los deseos de poder o de autoconservación. El estado político está concebido justamente para salvaguardar la identidad originaria del hombre. En Kant y en Pablo de Tarso, parecería a primera vista darse una modificación, pero lo que acontece en realidad es una potenciación de la identidad originaria, racional y espiritual, respectivamente.

Sin embargo, este estatismo identitario (que tanto en Kant como en Pablo de Tarso es primero desvío moral y luego retorno potenciado a la senda moral) no encuentra sustento en el mundo empírico. No resulta razonable aceptar que una divergencia (amén de su grado de banalidad), una ofensa (más allá de su justificación) o una confrontación (allende 
si es violenta o no) deje intactas las identidades de los involucrados. Necesariamente, la tensión entre la perspectiva de la primera persona y la perspectiva de la segunda persona trae consecuencias en el mundo y en la identidad de los agentes involucrados.

3. En Sí mismo como otro, Ricœur formula una teoría de la identidad personal que asume que cierto ámbito de la identidad es "cambiante, variable" (2013, p. XIII) e "implica la alteridad en un grado tan íntimo que no se puede pensar la una sin la otra" (p. XIV). Apoyado en la gramática, Ricœur sostiene (1) que el sí es un pronombre reflexivo que contiene todas las formas gramaticales; (2) que está "implicado de modo reflexivo en operaciones cuyo análisis precede al retorno hacia sí mismo" (1996, p. XXXI), y (3) que permite superar "la confrontación con la doble herencia -positiva y negativa- de las filosofías del sujeto” (2013, p. XIV). Así, Ricœur disocia la identidad en ídem y en ipse para dar cabida a aspectos permanentes y cambiantes en su análisis de la identidad. "[L] a mismidad como sinónimo de la identidad-ídem y le opondré la ipseidad por referencia a la identidad-ipse" (2013, p. XIII). Esta disociación vincula la identidad-ídem, o mismidad, a lo continuo y permanente en el sujeto. Por su parte, la identidad-ipse, o ipseidad, concierne a lo cambiante y sugiere que la alteridad es constitutiva de la mediatización histórica del sí.

La sospecha de que cierto aspecto de la identidad persiste más allá de la mismidad constituye el punto de partida de la reflexión de Ricœur sobre la identidad. Insatisfecho con los énfasis identitarios en la memoria y en la percepción, Ricœur analiza las operaciones de describir, narrar y prescribir con el propósito de determinar el ¿quién? que se halla por detrás de ellas: ¿quién habla? (locutor), ¿quién actúa? (agente), ¿quién se narra? (personaje de la narración) y iquién es el sujeto moral de la imputación? (sujeto de imputación moral) (2013, p. XIX). Al asociar cada una de estas preguntas a una capacidad, Ricœur formula la teoría del hombre capaz (homo capax) que responde a "la expresión modal Yo puedo" (Ricœur, 2002, p. 15).

Ricœur hace énfasis en las capacidades de actuar en el mundo y modificarlo (agencia) y de narrar los acontecimientos que acaecen (agencia narrativa) porque considera que "los acontecimientos de 
cualquier origen sólo se vuelven legibles e inteligibles cuando se cuentan dentro de una historia" (Ricœur, 2005, pp. 1-2). Entender narrativamente la identidad significa que "la persona, entendida como personaje de relato, no es una identidad distinta de sus experiencias" (Ricœur, 2013, p. 147). De tal modo, la historia del agente no se cierra sobre sí misma, sino que se construye reflexionada y progresivamente con el influjo de la alteridad y bajo la consigna de unidad de la contingencia y de la aleatoriedad de los acontecimientos. No se trata, en todo caso, de una narración sin sentido y al margen de la historia vivida y reflexionada.

De acuerdo con esto, la identidad es tributaria de un relato -con sentido y fruto de la reflexión- que se escribe y que se configura en los acontecimientos y el movimiento. En el relato de su vida, por intermedio de personajes históricos o ficticios, el agente da fundamento a la historia narrada, reconociéndose a sí mismo, modelando su identidad y contribuyendo a la modelación de la identidad de los otros agentes. Ricœur denomina identidad narrativa a esta "identidad de la historia [... que hace la identidad del personaje" (2013, p. 147).

Además de hacer de la teoría de la narrativa "el eje de la teoría de la acción y de la teoría moral” (2013, p. 124), Ricœur analiza la noción de identidad en relación con su permanencia en el tiempo a partir de las nociones de carácter y promesa, a la vez que define el carácter como "el conjunto de signos distintivos que permiten identificar de nuevo a un individuo humano como siendo el mismo" (2013, p. 113). Alude de este modo a la identidad-ídem, a saber, al conjunto de disposiciones con las que asociamos a un agente. El carácter refiere a los rasgos identitarios de un agente que permanecen y que lo hacen identificable, reconocible. Dado que no muda, el carácter acompaña al hombre hasta el último de sus días.

En el análisis presentado en el segundo apartado, se vio cómo las identidades de los agentes que soportan las argumentaciones de Hobbes, Kant y Pablo de Tarso coinciden con esta caracterización de la identidad como carácter, como ídem. Nada cuanto ocurre en el proceso de superación de la tensión entre la perspectiva de la primera persona y la perspectiva de la segunda persona (introducción de la 
perspectiva de la tercera persona) modifica la identidad de los agentes. Sin embargo, Ricœur plantea que una teoría de la identidad debe por necesidad dar cuenta de las afectaciones que el paso del tiempo y las interacciones sociales traen consigo. Por ello, aborda la identidad desde el punto de vista de la ipseidad, plantea que la identidad se construye cual relato de forma dinámica, y deriva en una síntesis de la multiplicidad de acontecimientos y de acciones que tienen lugar en la historia. Es gracias a esta síntesis, o hermenéutica de sí, que la identidad se configura y se hace unidad.

Como ninguna narración es "éticamente neutra" (Ricœur, 2013), sus componentes y sus formas de organización toman la forma de variaciones o anticipaciones imaginativas del juicio moral. A modo de "propedéutica de la ética" (Ricœur, 2013, p. 109), la narrativa evidencia "que el sujeto de la ética no es otro que aquel a quien el relato asigna a una identidad narrativa" (2013, p. 184). Así, la capacidad de narrar el mundo y la propia vida, esto es, la agencia narrativa, toma el resultado del ejercicio de la agencia (en cuanto capacidad de actuar) para, a partir de él, construir la identidad del agente moral de modo dinámico, en perspectiva histórica y bajo el influjo de la alteridad (ipseidad).

Al conectar las preguntas ¿quién narra?, ¿quién actúa? y ¿quién es el sujeto moral de imputación?, Ricœur vincula la capacidad de actuar en el mundo (agencia) con la capacidad de narrar el mundo y la propia vida (agencia narrativa) y con la capacidad de realizar juicios sobre lo bueno y lo malo y de ser, en consecuencia, responsable (agencia moral). Así, Ricœur plantea una ampliación de significado del concepto de agencia. A la luz de esta ampliación, la perspectiva de la primera persona constituye el conjunto de creencias que disponen al yo (1) a actuar en el mundo, (2) a narrar los acontecimientos que acaecen y (3) a realizar juicios que son expresados en oraciones como "Yo creo que la libertad es la máxima virtud de la sociedad".

Por su parte, la perspectiva de la segunda persona refiere ahora el conjunto de creencias que disponen al otro (1) a actuar en el mundo, (2) a narrar los acontecimientos que acaecen y (3) a realizar juicios que son expresadas en oraciones como "Tú crees que la igualdad es la máxima virtud de la sociedad". Se sigue entonces que la tensión entre 
la perspectiva de la primera persona y la perspectiva de la segunda persona es producto del ejercicio de la capacidad de actuar en el mundo (agencia), de la capacidad de narrar el mundo y la propia vida (agencia narrativa) y de la capacidad de realizar juicios sobre lo bueno y lo malo y de ser, en consecuencia, responsable (agencia moral). Amén de su índole y su contenido, esta tensión constituye la característica esencial de todo conflicto.

Retomo el caso de los vecinos para mostrar esta relación entre la agencia, la agencia narrativa y la agencia moral en el proceso de configuración de la identidad de un agente. Según lo planteado, dos vecinos, el uno católico y el otro protestante, habitan el mismo edificio y sostienen conjuntos de creencias distintos. Allende que uno es católico y el otro protestante, ambos comulgan con la raíz doctrinaria del cristianismo. Aceptan a Jesús como Christus, y a la Biblia como la Palabra de Dios. Si bien admiten el Decálogo como norma de vida, reivindican la síntesis que Jesús hizo de este en Mateo 22: 37-39 ("Jesús le dijo: Amarás al Señor tu Dios con todo tu corazón [..] Este es el primero y grande mandamiento. Y el segundo es semejante: Amarás a tu prójimo como a ti mismo"). Las acciones diarias de cada uno están alineadas como los valores más visibles sobre los que descansa la doctrina cristiana. Ninguno de los dos vecinos levanta falso testimonio, hurta o asesina.

Sin embargo, difieren en la comprensión de la experiencia religiosa y en la función atribuida a la comuna de Dios (ekklesia). Así, por una parte, el vecino católico reconoce la autoridad del papa y acepta el cuerpo de doctrina consignado en oraciones como el Credo. Entiende que la fe debe materializarse en obras y que la virgen y los Santos cumplen una indispensable función de mediación con Dios. Estas creencias soportan la acción del vecino católico y modelan la identidad que él tiene de sí y, particularmente, de su vecino protestante. Por otra parte, este último niega la autoridad del papa, rechaza los sacramentos, refuta la idea de purgatorio y considera innecesaria la intermediación de la Virgen y de los santos. Frente al énfasis que su vecino católico hace en la estructura eclesiástica, el vecino protestante se afianza en la consigna reformista "Sola Fides, Sola Scriptura". Estas creencias soportan la acción del vecino 
protestante y modelan la identidad que él tiene de sí y, en particular, de su vecino católico. Al tomar forma narrativa, estas creencias prefiguran y orientan el juicio moral de ambos vecinos.

Según se infiere de su contenido doctrinal, los valores que soportan la fe de cada vecino son incompatibles. Porque, en efecto, para el vecino católico no es un asunto menor la devoción a la Virgen María y el énfasis práctico de la fe. Y, para el vecino protestante, tampoco es menor el rechazo a la estructura clerical romana y el énfasis teórico de la fe. Las diferencias sobre estos asuntos doctrinarios y eclesiológicos son hondas. Por ello, es razonable suponer que, si no es tramitada correctamente, la desarmonía de estas creencias y valores podrá derivar en conflicto. Más allá del desenlace de este trámite, resulta evidente que entre el vecino católico y el vecino protestante existe una tensión en virtud de sus respectivos conjuntos de creencias.

El caso de los dos vecinos refiere la perspectiva de la primera persona y la perspectiva de la segunda persona. Las agencias de cada vecino se ponen en obra conforme realizan una acción en el mundo con base en sus respectivos conjuntos de creencias; a su vez, sus agencias narrativas funcionan con fundamento en los valores implícitos en estos conjuntos de creencias y, cual relato, modelan dinámicamente sus identidades y las de los otros; y, por último, sus agencias morales operan cuando, con base en sus respectivos conjuntos de creencias prácticas (valores), cada uno de ellos elabora juicios sobre lo bueno y lo malo, aspira a realizar plenamente su ser en pos de su ideal de vida buena y es, en consecuencia, objeto de imputación moral.

4. En la Pequeña ética, ${ }^{2}$ Ricœur formula una ética orientada a la creación de universales que consideren las especificidades de los contextos en la aplicación de las normas universales. Ricœur diferencia los conceptos de ética y moral, atribuyendo a aquella la búsqueda de la vida buena (estima de sí) y a esta la conformidad con los términos de la obligación moral (respeto de sí). De esta diferenciación Ricœur extrae el fundamento para los universales en contextos, que es la armonización entre las éticas teleológica

Así son conocidos los capítulos 7, 8 y 9 de Sí mismo como otro. 
(Aristóteles) y deontológica (Kant) que guía el "recurso al objetivo ético, cuando la norma conduce a atascos prácticos” (2013, p. 175).

Ricœur define la intencionalidad ética como la búsqueda de la vida buena que se lleva a cabo en tres momentos (2013, p. VIII): "I. Tender a la "vida buena" / II. Con y para el otro / III. En instituciones justas" (ética teleológica-aristotélica). El primer momento de la intencionalidad ética corresponde, en clave aristotélica, a la búsqueda de un bien particular que satisfaga las necesidades y asegure el bienestar. Esta búsqueda es individual y sus contenidos varían de agente en agente. Así, un agente desarrolla su objetivo ético en tanto persigue su concepción particular de felicidad. A la vez que es constitutiva de la identidad-ipse, la búsqueda del objetivo ético de la vida buena se sustenta en la estimación de las propias capacidades, a saber, "la capacidad de actuar intencionalmente [y] la capacidad de introducir cambios en el curso de las cosas" (Ricœur, 2007, p. 243). Estas capacidades repercuten en el concepto de agencia y provocan en ella una ampliación de significado: agencia, agencia narrativa y agencia moral. Así, la capacidad de actuar se conecta con la capacidad de narrar el mundo y la propia vida (agencia narrativa) y con la capacidad de realizar juicios sobre lo bueno y lo malo y de ser, en consecuencia, responsable (agencia moral).

La perspectiva de la primera persona se configura en este primer momento de la intencionalidad ética a partir de la búsqueda de un buen vivir. Como mencioné en el primer apartado, la perspectiva de la primera persona se constituye a partir de un conjunto de creencias que disponen al yo a actuar y que son expresadas en oraciones como "Yo creo que la libertad es la máxima virtud de la sociedad". Estas creencias se articulan al propósito superior de alcanzar la realización plena del ser -esto es, “'vivir-bien', 'vida buena': 'verdadera vida” (Ricœur, 2013, p. 177)-, el cual seguirá siendo abstracto "mientras le falte la estructura dialógica introducida por la referencia al otro" (2013, p. 176). De ahí que la perspectiva de la primera persona y la perspectiva de la segunda persona compartan la búsqueda de la vida buena como un aspecto de la vida práctica.

El segundo momento de la intencionalidad ética sugiere que la estima de sí se complementa con la solicitud del otro (2013, 
p. 186). Ricœur define el "hermoso nombre de la solicitud [...] como espontaneidad benevolente" (2013, p. 222) y afirma que ella está constituida por dimensiones estructurales como la reversibilidad (de roles), la insustituibilidad (de las personas) y la similitud (entre los sujetos en cuanto capaces). La solicitud "despliega [...] la dimensión dialogal implícita en ella" y no puede "vivirse y pensarse sin la estima de sî" (2013, p. 243). En este segundo momento, se rebasa el ámbito de la ipseidad, y queda planteada la necesidad inminente de "la estructura dialógica introducida por la referencia al otro" (2013, p. 176). Como en la configuración de la identidad, la alteridad es indispensable y, sin ella, la concreción del objetivo ético se torna imposible. Según esto, antes que tensión, es extensión y complementariedad lo que se da entre la perspectiva de la primera persona y la perspectiva de la segunda persona.

La estima de sí lleva, para Ricœur, implícita la conciencia sobre los efectos que las acciones propias tienen en la vida de los demás. De esta conciencia Ricœur deriva dos tesis: la responsabilidad por sí mismo y por el otro, y el entrecruzamiento de los proyectos de vida. Estas dos tesis son importantes para la comprensión del sí y para la configuración del segundo momento de la intencionalidad ética, porque, contra filosofías del derecho natural que presuponen al sujeto revestido de derechos que son anteriores de la inserción en el mundo social, Ricœur sugiere una comprensión de la persona no contingente ni revocable, reivindicando "la función mediadora entre capacidad y efectuación” (2013, p. 188).

Esta función mediadora es puesta en contexto por Ricœur por medio de la comprensión de la amistad, la cual no anula la estima de sí, sino que, como la Regla de Oro, añade "la idea de reciprocidad en el intercambio entre humanos que se estiman mutuamente" (2013, p. 195). Del mismo modo como la estima de sí supone que uno ama lo mejor de sí, el amigo desea para su amigo que siga siendo lo que es. Esta idea de reciprocidad remite a las condiciones bajo las cuales la relación con el otro debe darse. De un lado, define al otro como único e insustituible. Así, el sujeto no solo es un sí mismo que se estima a sí, sino que el conjunto de su vida se articula con los otros entretejiendo activamente sus proyectos de vida. 
De otro lado, presupone una instancia de reconocimiento mutuo que Ricœur denomina gratitud ("Lo que es sin precio, entonces, no es el don en sí mismo, el objeto intercambiado, sino el dar en tanto que tal, este gesto cuasi mágico del reconocimiento mutuo, donde individuación y gratitud se entremezclan”, 2013, p. 391). Así como la alteridad contribuye a la configuración de la ipseidad, el reconocimiento del otro (que se da sin interés comercial) amplía la estima de sí a la estima del otro y origina una dinámica de reciprocidad basada en el respeto.

El tercer momento de la intencionalidad ética sostiene que "[e]n la noción misma del otro está implicado que el objetivo del bien-vivir incluya, de alguna manera, el sentido de la justicia" (Ricœur, 2013, p. 202). Conforme a esto, el proyecto de vida buena no es posible sin el concurso de la alteridad y de las instituciones justas. A estas últimas Ricœur les atribuye "la estructura de vivir juntos de una comunidad histórica” (2013, p. 203), así como el incremento de la solicitud por el otro y el fomento de la estima de sí. Al incentivar la pluralidad, la justicia pone en evidencia que los proyectos de vida se entretejen y comprometen a los demás, que son iguales al sí mismo.

En relación con la tensión que expuse anteriormente entre la perspectiva de la primera persona y la perspectiva de la segunda persona, Ricœur plantea la estrategia de introducir la perspectiva de la tercera persona, pero atribuyéndole una impronta no coactiva. Al margen de las "restricciones vinculadas a los sistemas jurídicos y a la organización política”, la perspectiva de la tercera persona de Ricœur (institución) refiere "la estructura del vivir juntos de una comunidad histórica, estructura irreducible a las relaciones interpersonales" (2013, p. 203). Este "querer vivir juntos" constituye un componente crucial de la materialización de la intencionalidad ética, que se diferencia en tres sentidos de las soluciones a la tensión expuestas en el segundo apartado: las de Hobbes, Kant y Pablo de Tarso.

En primer lugar, más que constructo limitante de la injerencia de los otros, la institución constituye la instancia de efectuación de la buena vida que sella la unión entre la perspectiva de la primera persona y la perspectiva de la segunda persona. El sí mismo precisa de ella tanto como precisa de la solicitud que hace el otro para hacer 
posible su vida buena. En segundo lugar, la institución no descansa en una fundamentación prudencial ni jurídica. De naturaleza ética, la institución constituye el encuentro ético con el otro en un ámbito superior al interpersonal. Se trata, en términos de Hannah Arendt, de la diferencia entre poder común y dominación, entre potentias y potestas. Así, el "poder común sólo existe en la medida en que el querer vivir y actuar en común subsiste dentro de una comunidad histórica” (Ricœur, 2013, p. 279). En tercer lugar, Ricœur no parte de la asunción de la separación de los sujetos ni concibe las identidades como si ellas no experimentaran cambios en el tiempo. En sintonía con su teoría de la identidad, para Ricœur todo cuanto ocurre en la tensión entre la perspectiva de la primera persona y la perspectiva de la segunda persona y en su resolución, la instauración de la institución, modifica de modo ostensible los aspectos básicos de la identidad del agente.

Pese a sostener "la primacía de la ética sobre la moral", Ricœur plantea que el objetivo ético de la búsqueda de la vida buena debe pasar "por el tamiz de la norma" (2013, p. 175). La universalización del objetivo ético recupera la exigencia kantiana de extender la máxima ética al estatuto de racionalidad universal. Para Ricœur, esta construcción autonómica de la norma obliga su observancia -de hecho, la "obediencia verdadera [...] es la autonomía" (2013, p. 222)-, y constituye la forma adecuada para articular la estima de sí y el respeto de sí, que es aquella "pasada por el tamiz de la norma universal y limitadora, en una palabra, la estima de sí bajo el régimen de la ley" (2013, p. 228).

Según se anticipó en la introducción del presente apartado, Ricœur formula una ética de la alteridad que busca armonizar los contenidos de las éticas teleológicas y deontológicas. Esta armonización, que guía el "recurso al objetivo ético, cuando la norma conduce a atascos prácticos" (2013, p. 175), se sustenta en la noción aristotélica de "sabiduría práctica, sabiduría referida al juicio moral en situación, y para la cual la convicción es más decisiva que la regla misma” (2007, p. 252). Para Ricœur, siguiendo a Aristóteles, la sabiduría práctica constituye la capacidad de configuración permanente del sí mismo. Su utilidad no es ocasional. No está reservada para casos 
límites o para decisiones existenciales cruciales. Se trata, más bien, "de una capacidad que puede ser ejercida en los diferentes dominios en los que la vida humana se constituye" (Domingo Moratalla, 1998, p. 140). Así, se trata de una instancia de mediación entre la deliberación y la decisión que permite dirimir entre dos opciones contrapuestas de un mismo peso o valor.

En la formulación kantiana, el paso del objetivo ético por el tamiz de la norma moral es resuelto por medio del imperativo categórico, que estriba en la elevación a estatuto universal de la máxima subjetiva de acción. Merced a la abstracción de los propios fines y de la eliminación del influjo de las inclinaciones, el paso al plano ético se torna expedito; ello disipa de antemano toda suerte de atasco práctico (trayecto de efectuación). Como Kant, Ricœur cree que el trayecto de justificación (esto es, el paso del objetivo ético por el tamiz de la norma moral) se funda en la adecuación (epistémica) de las máximas de acción con la ley universal. Sin embargo, para Ricœur, el trayecto de justificación no siempre arroja luz sobre las condiciones prácticas de aplicación. Es dable que un agente, merced al trayecto de justificación, no sepa con certeza qué hacer en el trayecto de efectuación en tanto ha admitido dos principios antagónicos que él considera de obligatorio cumplimiento. De tal suerte, los "conflictos más significativos que suscita la pretensión de universalidad de la moral nacen a propósito de deberes supuestamente derivados que quedan presos, al mismo tiempo, en la ganga contextual de una cultura histórica" (Ricœur, 2013, p. 303).

Un ejemplo puede ilustrar esto último. Piénsese en un agente que sostiene un conjunto de creencias en el que se destacan dos: S1 "amar a la familia" y S2 "perdonar las ofensas recibidas". Estas creencias (S1 y S2) rigen la vida del agente y definen los términos bajo los cuales su intencionalidad ética se lleva a cabo. Enfrentado al trayecto de justificación, el agente se halla dispuesto a llevar a la instancia universal sus máximas éticas de "amar a la familia" y "perdonar las ofensas recibidas". Prima facie, parece no existir ninguna oposición entre S1 y S2, pues se puede seguir la creencia de amor filial (amar a los miembros de la familia) al tiempo que se sigue la creencia cristiana del perdón (perdonar las ofensas recibidas). 
Pese a esto, en el trayecto de efectuación puede surgir un problema de aplicación de ambas creencias (que han adquirido ya la forma de mandatos o principios) cuando, por ejemplo, las ofensas recibidas afectan a un integrante de la propia familia. Allí el mandato de perdonar se hace difícil de practicar en virtud de que el destinatario de la ofensa es una persona que el agente se ha comprometido a amar. Téngase presente que S1 y S2 definen los términos bajo los cuales su intencionalidad ética se lleva a cabo. No se trata de creencias intrascendentes o banales. Se trata de creencias vitales que dan forma y estructura a un proyecto de vida buena. Aclaremos esto por medio de un ejemplo concreto.

Pensemos el caso de Silvia, una mujer a la cual un grupo alzado en armas le ha asesinado tres de sus cinco hermanos. Asociemos a ella las creencias S1 y S2. De acuerdo con S1, amar a la familia es un mandato incondicional. Parece razonable suponer que este amor se traduce en la cotidianidad en defensa y en reivindicación. De acuerdo con S2, perdonar constituye el curso de acción ideal frente a las ofensas. Si nos atenemos a la formulación kantiana del imperativo categórico no deberíamos preocuparnos por la armonía epistémica de las máximas éticas (en este caso, S1 y S2) que han alcanzado el estatuto de racionalidad y universalidad, porque el trayecto de fundamentación está concebido de modo que estén aseguradas de antemano tanto su armonía epistémica cuanto su aplicación práctica. Sin embargo, el caso en cuestión plantea la imposibilidad de aplicar, a la vez, S1 y S2, puesto que a Silvia le resulta difícil amar a su familia y, simultáneamente, perdonar al asesino de sus hermanos. Amar y perdonar emergen como dos mandatos que, a la luz de la situación, son irreconciliables.

Ilustremos esta perplejidad mediante otro ejemplo. Pensemos ahora el caso de Víctor Hugo, un campesino que, ante las injusticias de la sociedad en la que vive, decidió formar parte de un grupo alzado en armas que propende por la justicia social y la igualdad de oportunidades. Como Silvia, Víctor Hugo sostiene un conjunto de creencias que rigen su vida como agente y que definen los términos bajo los cuales su intencionalidad ética se lleva a cabo.

Del conjunto de creencias de Víctor Hugo, resaltemos dos: V1 "propender por las condiciones dignas de la vida humana" y V2 
"luchar por la justicia social". De acuerdo con V1, la vida de todo ser humano es valiosa y debe, por lo tanto, desarrollarse en condiciones mínimas de dignidad. De acuerdo con V2, la justicia es una virtud social que demanda la implementación de todos los medios posibles. Así, en orden a alcanzarla, el ser humano debe ocuparse por distintos medios y recursos de su materialización. En tal sentido, y enfrentado al trayecto de justificación, Víctor Hugo está dispuesto a llevar a la instancia universal sus máximas V1 y V2. Prima facie, parece no existir ninguna oposición entre V1 y V2. Sin embargo, su ejercicio como integrante de un grupo alzado en armas lo lleva a realizar acciones derivadas de V2 (verbigracia, secuestrar, extorsionar o asesinar) que ponen en cuestión el núcleo básico de Vl, que es la vida. Como en el caso descrito de Silvia, "propender por las condiciones de la vida humana" y "luchar por la justicia social" emergen como dos mandatos que, a la luz de la situación, son irreconciliables.

Para este tipo de aporías del deber (S1 vs. S2; V1 vs. V2), Ricœur hace uso de la noción de sabiduría práctica. El recurso al objetivo ético, que sustenta el empleo de la sabiduría práctica, sugiere una mediación entre la deliberación y la decisión por parte del agente moral en orden a dirimir entre dos opciones contrapuestas del mismo peso o valor (a saber, S1 vs. S2 o V1 vs. V2).

Conforme a esto, la sabiduría práctica se pone en obra por medio de un compromiso reflexivo de llevar a cabo un "juicio en situación dentro del ámbito de los conflictos” (Ricœur, 2013, p. 317). Llevado al ámbito de la confrontación con otro agente que sostiene un conjunto de creencia antagónico, Ricœur sugiere que la sabiduría práctica actúa "a través del debate público, el coloquio amistoso, las convicciones compartidas" (2013, p. 320), e implica la consideración de que el otro es único, valioso per se e irremplazable. De este modo, se descarta todo tratamiento que minusvalore la condición del otro, que no se funde en el reconocimiento y que no derive en respeto.

5. De acuerdo con lo expuesto en los apartados anteriores, la perspectiva de la primera persona y la perspectiva de la segunda persona toman forma y estructura a partir de la unión de tres diferentes -pero complementarios- tipos de agencia, a saber: (1) la 
capacidad de actuar (agencia), (2) la capacidad de narrar el mundo y la propia vida (agencia narrativa) y (3) la capacidad realizar juicios sobre lo bueno y lo malo (agencia moral). Así, un agente conduce su vida con arreglo a sus creencias y valores y, en ese proceso vital, interactúa con otros agentes. Asimismo, un agente (perspectiva de la primera persona) construye su historia en la interacción con el mundo y con los otros agentes (perspectiva de la segunda persona). En la síntesis que hace de tal interacción, él construye su identidad.

Un agente sostiene un conjunto de creencias que, amén de su índole, permiten la actuación en el mundo en orden a realizar plenamente el ser, a saber, la vida buena. Este dato es constitutivo tanto de la perspectiva de la primera persona cuanto de la perspectiva de la segunda persona. Por ello, no parece razonable que exista algún agente que no aspire a realizar plenamente su ser y no busque su particular concepción de vida buena. Sí parece razonable por el contrario que cada agente trata -en la medida de sus capacidades- de asegurar las condiciones para la materialización de su proyecto de vida buena.

Según lo anterior, la agencia moral se expresa concretamente mediante juicios del tipo "Yo debo hacer cuanto esté al alcance de mis capacidades para materializar mi proyecto de vida buena". Esto, en el contexto de una instancia posterior a un conflicto, toma razonablemente la forma de "Yo debo reconciliarme con el Tú en tanto ello contribuya a la materialización de mi proyecto de vida buena”. Y, a su vez, obliga a que el significado atribuido a la agencia moral experimente una variación de significado, ya que, además de referir la capacidad de realizar juicios sobre lo bueno y lo malo, implicará la priorización del "objetivo de la vida buena con y para los otros en instituciones justas” (Ricœur, 2013, p. 258), así como la capacidad práctica de deliberar y decidir cursos de acción orientados a materializar el proyecto de vida buena. Compartida por la perspectiva de la primera persona y por la de la segunda persona, esta capacidad constitutivamente ética no se reduce a un puro conocimiento lógico de las ganancias de la reconciliación, sino que refiere, ante todo, una disposición guiada por el resultado del recurso ético, que es la sabiduría práctica, y orientada a actuar en función de los tres momentos de la intencionalidad ética. 
El recurso ético no niega -recuérdese- el importe epistémico de la norma moral, pero sí advierte el atasco práctico al que conduce, esto es, la dificultad del trayecto de efectuación derivada de "una moral de la obligación [que] engendra situaciones conflictivas" (Ricœur, 2013, p. 259). En esta medida, el recurso ético comporta un juicio moral en situación que facilita el trayecto de efectuación y que se atempera tanto por las condiciones prácticas de la situación como por las condiciones identitarias del agente. Este juicio moral, posible en virtud de la sabiduría práctica, armoniza los contenidos de los mandatos o principios antagónicos y proyecta, justifica y dinamiza una armonización ética.

Analizada en un ámbito formal, la mencionada armonización ética estriba en la tramitación efectiva de la contraposición de principios o mandatos de acción que comparten un equivalente estatuto epistémico y normativo. Este escrutinio deliberativo respecto de los principios de acción (esto es, la renuncia al bloque de parcialidad) deriva en la invención de "comportamientos justos y apropiados a las singularidades de los casos, aunque no por ello, está abandonado a la arbitrariedad" (Ricœur, 2013, p. 271).

Analizada en un ámbito práctico, la armonización ética presupone la ponderación de los aspectos cambiantes (mismidad) y estáticos (ipseidad) de las identidades de los agentes (la perspectiva de la primera persona y la de la segunda persona), así como de las condiciones motivacionales y racionales de cada agente. Este aspecto relativo a la justificación motivacional de la reconciliación es un asunto subestimado por buena parte de las teorías de la reconciliación.

La respuesta basada en la armonización ética de la reconciliación considera, por el contrario, las motivaciones -racionales y emocionales- del sí mismo y del otro, a partir de una comprensión no estática de la identidad, esto es, cambiante, narrativa y basada en la mediatización histórica de la alteridad. Por tanto, no se trata de una armonización ética que, basada en una fundamentación de índole racional, determine la obligatoriedad moral de la reconciliación, esto es, el restablecimiento de las relaciones del sí mismo y el otro. Se trata, más bien, de una armonización que surge como consecuencia de la valoración armonizada de las emociones, de las 
creencias sostenidas y de las dificultades prácticas -internas y externas- de la deliberación y de la elección.

En relación con la tensión entre la perspectiva de la primera persona y la perspectiva de la segunda persona, la armonización ética guarda relación con la orientación directiva a "querer vivir juntos", contenida en el tercer componente de la intencionalidad ética. Más allá de las "restricciones vinculadas a los sistemas jurídicos y a la organización política", la noción de institución justa refiere "la estructura del vivir juntos de una comunidad histórica, estructura irreducible a las relaciones interpersonales" (Ricœur, 2013, p. 203). Este "querer vivir juntos" constituye un componente crucial de la materialización de la intencionalidad ética, que constituye la instancia de efectuación del objetivo ético de la buena vida para todos.

Con el fin de ilustrar el funcionamiento de la armonización ética, vuelvo al caso de Silvia y Víctor Hugo. Como dije, ambos son agentes que sostienen conjuntos distintivos de creencias. De un lado, Silvia sostiene S1 "amar a la familia", y S2 "perdonar las ofensas recibidas". Por otro lado, Víctor Hugo sostiene V1 "propender por las condiciones de la vida humana", y V2 "luchar por la justicia social". Silvia es la hija menor de una familia tradicional e influyente del municipio, y Víctor Hugo es un jefe guerrillero de origen campesino. Ambos se conocen desde la infancia y aspiran a lo mejor para sí y para el municipio. Difieren en todo caso en los medios para concretar dicho fin. De hecho, esta diferencia respecto de los medios desató una serie de acontecimientos que provocó la ruptura de sus relaciones. Veamos.

Víctor Hugo nació en la misma localidad de Silvia y sus hermanos. Ante las pocas oportunidades de trabajo y de cambio institucional, a la edad de 20 años Víctor Hugo decidió enlistarse en un grupo guerrillero que propende por una transformación de las condiciones de vida de los habitantes del municipio. Como muchos de sus coterráneos, Víctor Hugo cree que las familias ricas -como la de Silvia- han ejercido desde siempre un nocivo control sobre la administración pública y han sumido en la pobreza a sus habitantes. Víctor Hugo considera esto injusto y, basado en ello, justifica el uso de la violencia en contra de quienes han cometido actos de corrupción. 
En el proceso de esta reivindicación social, Víctor Hugo lideró varias operaciones en contra de la familia de Silvia, que ocasionaron la muerte de tres de sus hermanos. Pese a lamentar la muerte de un ser humano, Víctor Hugo aún cree que su causa está justificada. No considera, por tanto, que las operaciones que lideró hayan estado mal, ni que deba recibir un castigo por ellas.

La contraparte de la historia, Silvia, hace parte de una de las familias más influyentes del municipio. De un total de cinco hermanos, Silvia ha perdido a tres en el contexto de las ocupaciones efectuadas por la guerrilla que comanda Víctor Hugo. Dos de sus hermanos fueron hallados sin vida en la plaza central, mientras que el otro permanece aún desaparecido. El grupo guerrillero que opera en la zona se ensañó con la familia de Silvia por cuenta de la participación política de su padre y de sus hermanos. Al ser preguntada por lo acontecido, Silvia expresa dolor y rabia, y endilga toda la responsabilidad a la guerrilla. A su juicio, no existe justificación alguna para los actos del grupo insurgente y niega que exista un modo para resarcir el daño causado. Considera de este modo que los guerrilleros, comenzando por Víctor Hugo, deben recibir el máximo castigo posible y que debe negárseles cualquier tipo de amnistía judicial, toda vez que la única sanción aceptable es la privación efectiva de la libertad.

El conflicto entre Silvia y Víctor Hugo es la manifestación en micro de la tensión entre agentes que profesan diferentes conjuntos de creencias. Desde el punto de vista de la armonización ética, estos conflictos son manifestación de la tensión entre la perspectiva de la primera persona y la perspectiva de la segunda persona, y su solución pasa por la armonización de los valores que sustentan sus respectivos conjuntos de creencias. Así, enfrentados a restablecer sus relaciones, a reconciliarse, los agentes (Silvia y Víctor Hugo) deberán identificar el objetivo ético propio y admitir el hecho de que el otro persigue su propio objetivo ético. Este encuentro con el otro llevará implícito el reconocimiento de que el otro, un distinto al sí mismo, existe y puede hacer y evaluar sus acciones. ${ }^{3}$

En tal medida,"[y]o soy ese otro que puede evaluar sus acciones y, estimando buenos los fines de algunas de ellas, es capaz de evaluarse a sí mismo, de estimarse bueno. El discurso 
Tras esto, Silvia y Víctor Hugo deberán gestar una diferenciación entre el momento en el que tuvo lugar la ofensa (el asesinato de los hijos de Doña Rosa, madre de Silvia, y el poder ejercido injustamente sobre la administración pública) y el momento presente. Esta diferenciación pondrá de manifiesto el movimiento histórico y narrativo en sus respectivas identidades y dará cuenta de la mediatización histórica de la alteridad en la constitución de la identidad propia. En su condición de "propedéutica de la ética" (Ricœur, 2013, p. 109), la narrativa auspiciará la reconfiguración de lo sucedido y posibilitará, a su vez, la actualización de las respectivas identidades.

En virtud de que la intencionalidad ética se lleva a cabo "con y para otro en instituciones justas" (Ricœur, 2013, p. 186), la reconfiguración narrativa de la historia en común y de sus identidades les permitirá a Silvia y a Víctor Hugo reconocer que sus respectivos objetivos éticos se encuentran vinculados, y que la institución, su municipio, es un otro que carece de rostro, pero que está ahí y que le hace solicitudes a cada uno. Así, este paso de la estima de sí al respeto de sí hará posible un círculo virtuoso entre Silvia y Víctor Hugo en el que la libertad y la vida buena emergerán como posibles en el contexto de las normas de convivencia. Desde luego, el contenido de esas normas será válido en tanto y en cuanto sirva para la satisfacción de los objetivos éticos de vida buena de Silvia y Víctor Hugo.

\section{Palabras finales}

Empleando como fundamento la hermenéutica de sí de Paul Ricœur, en el presente estudio presenté una respuesta basada en la armonización ética a la pregunta por la posibilidad de la reconciliación. De este modo, sostuve que es posible restablecer las relaciones humanas después de sucedido un conflicto por medio de la armonización ética de conjuntos de creencias antagónicos, la cual se fundamenta (1) en una comprensión de la identidad cambiante, narrativa y mediatizada históricamente por la alteridad, y (2) en la asunción

del 'yo puedo' es, sin duda, un discurso en yo. Pero el acento principal hay que ponerlo en el verbo, en el poder-hacer, al que corresponde, en el plano ético, el poder-juzgar" (Ricœur, 2013, p. 187). 
de que los proyectos de vida del yo y del otro se entretejen activamente en el contexto de instituciones justas. A diferencia de Ricœur, que la emplea para resolver lo que él denomina aporías del deber, en la armonización ética la noción de sabiduría práctica aporta una estrategia de armonización entre conjuntos de creencias incompatibles que disuelve la tensión entre la perspectiva de la primera persona y la perspectiva de la segunda persona sin adjuntar una instancia normativa como la planteada por Hegel (Sittlichkeit). La respuesta basada en la armonización ética aporta así una solución plausible a la tensión conforme ella se presenta en contextos de transición institucional (de la guerra a la paz, de la dictadura a la democracia) como en contextos interpersonales $\mathbf{I}$

\section{Referencias}

Auerbach, Y. (2004). The Role of Forgiveness in Reconciliation. En Y. BarSiman-Tov (Ed.), From Conflict Resolution to Reconciliation (pp. 149176). Oxford University Press.

Bhargava, R. (2001). Restoring Decency to Barbaric Societies. En D. F. Thompson, \& R. I. Rotberg (Eds.), Truth v. Justice: The Morality of Truth Commissions (pp. 45-67). Princeton University Press.

Brounéus, K. (2008). Analyzing Reconciliation: A Structured Method for Measuring National Reconciliation Initiatives. Peace and Conflict, 14(3), 291-313. https://doi.org/10.1080/10781910802017354.

Domingo Moratalla, T. (1998). La configuración de la filosofía de Paul Ricœur. En J. Masiá Clavel, T. Domingo Moratalla y A. Ochaita Velilla (Eds.), Lecturas de Paul Ricour (pp. 125-140). Universidad Pontificia Comillas.

Dussel, E. (2012). Pablo de Tarso en la filosofía política actual y otros ensayos. Ediciones Paulinas.

Ghali, B. (1992). Agenda for Peace. United Nations. http://www.undocuments.net/a47-277.htm.

Hazan, P. (2009). Reconciliation. En V. Chetail (Ed.), Post-Conflict Peacebuilding: A Lexicon (pp. 256-267). Oxford University Press. 
Hobbes, T. (1994). Leviatán: La materia, forma y poder de un Estado eclesiástico y civil (C. Mellizo, Trad.). Alianza.

Kant, I. (1985). Filosofía de la historia (E. Ímaz, Trad.). Fondo de Cultura Económica.

Kant, I. (1996). Fundamentación de la metafísica de las costumbres (J. M. Mardomingo, Trad.). Ariel.

Little, A., \& Maddison, S. (2017). Reconciliation, transformation, struggle: An introduction. International Political Science Review, 38(2), 145-154. https://doi.org/10.1177/0192512116681808.

Murphy, C. (2010). A Moral Theory of Political Reconciliation. Cambridge University Press.

Paris, R. (2005). At War's End: Building Peace After Civil Conflict. Cambridge University Press.

Peirce, C. S. (1988). La fijación de la creencia. En Charles S. Peirce. El hombre, un signo (El pragmatismo de Peirce) (pp. 175-199) (J. Vericat, Trad.). Crítica.

Philpott, D. (2012). Just and Unjust Peace An Ethic of Political Reconciliation. Oxford University Press.

Ricœur, P. (2002). Prefacio. En M. F. Begué, La poética del sí mismo (pp. 13-17). Biblos.

Ricœur, P. (2005). Volverse capaz, ser reconocido. Internet Archive. https:// bit.ly/3a7YczP.

Ricœur, P. (2007). Ética y moral. En C. Gómez (Ed.), Doce textos fundamentales de la Ética del siglo xx (pp. 241-255). Alianza.

Ricœur, P. (2013). Sí mismo como otro (A. Neira, Trad.). Siglo XXI.

Schreiter, R. (2005). Reconciliation and Healing as a Paradigm for Mission. International Review of Mission, 94(372), 74-83. https:/doi. org/10.1111/j.1758-6631.2005.tb00487.x.

Soares de Oliveira, R. (2011). Illiberal Peacebuilding in Angola. Journal of Modern African Studies, 49(2), 287-314. https://doi.org/10.1017/ S0022278X1100005X. 
Ugarriza, J. E., \& Nussio, E. (2017). The Effect of Perspective-Giving on Postconflict Reconciliation. An Experimental Approach. Political Psychology, 38(1), 3-19. https://doi.org/10.1111/pops.12324.

Verdeja, E. (2009). Unchopping a tree: Reconciliation in the aftermath of political violence. Temple University Press. 